\title{
О СПОСОБАХ АКТУАЛИЗАЦИИ ГЛАГОЛЬНЫХ ФОРМ В СТИХОТВОРЕНИЯХ ВЕРЫ ПОЛОЗКОВОЙ
}

\author{
О.О. СКОРОБОГАТОВА, С.О. СТРЕЛЬЧЕНКО. ПРО СПОСОБИ АКТУАЛІЗАЦІЇ
} ФОРМ ДІЕСЛОВА В ПОЕЗІЯХ ВІРИ ПОЛОЗКОВОЇ.

Новизна роботи пов'язана з тим, що актуалізація форм $i$ значень атрибутивних $i$ особових форм дієслова, протиставлення дієслівних значень стану, способу $i$ часу, використання яких є значущим у змістовній організації тексту, відіграє в поезіях В. Полозкової велику роль, але досі не було предметом комплексного дослідження. Згущення та співпозиція $\epsilon$ загальнопоетичними прийомами, щчо є типовими для російськомовної поезії $X X-X X I$ століть, але їхнє функиіонування має ідіостильові риси. Мета роботи - проаналізувати низку поезій Віри Полозкової, в яких спостерігається згущення різних форм дієслова (дієприкметника, способу $i$ часу, iз заперечною часткою) $i$ протиставлення значень способу $i$ часу. Проаналізовано граматичну організацію віршів "Думала - сами ищем...», "Исписанными блокнотами, слезами, шагами, сквотами...», «Не окрыляет. Не властвует. Не влечёт...». Дослідження ичих і низки інших поезій Віри Полозкової дозволяс дійти висновку про те, щэо поетка активно використовує морфологічний потенціал форм дієслова. Ï̈ ідіостиль характеризує актуалізація форм дієприкметника, неозначеної форми й особових форм дієслова. Використовується виразний $і$ виражальний потениіал категорій стану, способу, часу. Автори статті стверджують, що співпозиція, селекиія й атракиія допомагають поету підкреслити граматичну семантику форм дієслова. Активне співположення й відбір дієприкметникових форм є ідіостильовою характеристикою лірики Полозкової.

Ключові слова: віршовий текст, поетична морфологія, домінанта, згущення, співпозиція, атракиія, ідіостиль, Віра Полозкова.

\section{Е.А. СКОРОБОГАТОВА, Е.А. СТРЕЛЬЧЕНКО. О СПОСОБАХ АКТУАЛИЗАЦИИ ГЛАГОЛЬНЫХ ФОРМ В СТИХОТВОРЕНИЯХ ВЕРЫ ПОЛОЗКОВОЙ.}

Новизна работы определяется тем, что актуализация форм и значений атрибутивных и личных форм глагола, противопоставление глагольнылх значений залога, вида и времени, использование которых значимо для смысловой организачии стихотворного текста, играет в лирике Полозковой весомую роль, но до сих пор не было предметом специального комплексного исследования. Сгущение и соположение являются общепоэтическими приемами, типичными для русскоязычной поэзии XX-XXI веков, при этом их функиионирование имеет идиостилевые чертыл. Цель работы - проанализировать ряд стихотворений Веры Полозковой, в которых наблюдается сгущение различных глагольных форм (причастных, вида и времени, с отрицательной частицей) и противопоставление значений вида и времени. Проанализирована грамматическая организаџия стихотворений "Думала - сами ищем...», "Исписанными блокнотами, слезами, шагами, сквотами...», «Не окрыляет. Не властвует. Не влечёт...». Исследование морфологического рисунка этих и ряда других стихотворений Веры Полозковой позволяет сделать вывод о том, что поэт активно использует морфологический потенциал глаголов и глагольных форм. Для ее идиостиля характерна актуализачия причастных форм, инфинитива и личных форм глагола. Особенно активно используется выразительныий потенциал категорий залога, времени и вида. Доказывается, что соположение, отбор и аттракиия помогают поету подчеркнуть грамматическую семантику глагольных форм. Активное соположение и отбор причастных форм являются идиостилевой характеристикой лирики поэта.

Ключевые слова: стихотворный текст, поэтическая морфология, доминанта, сгущение, соположение, аттракиия, идиостиль, Вера Полозкова.

O.O. SKOROBOGATOVA, E.O. STRELCHENKO. ABOUT THE WAYS OF ACTUALIZATION OF VERB CONSTRUCTIONS IN VERA POLOZKOVA'S VERSES.

The novelty of the work is determined by the fact that the actualization of the forms and meanings of atributive and finite forms of the verb, the opposition of the verbal meanings of voice, aspect

(C) Е.А. Скоробогатова, Е. Стрельченко, 2019

https://doi.org/10.34142/2312-1572.2019.02.68.02 
and tense, the use of which in the lyrics reflects individual style character, has not been the subject of a particular complex study so far. Compression and juxtaposition are general poetic ways characteristic of the Russian-language poetry of the XX - XXI centuries, however their usage can be differentiated enormously in various individual style. The goal of the work is to analyze a series of Vera Polozkova's verses, where different verb forms compression (participial, aspect and tense, negative) and opposition of the meanings of aspect and tense can be noted. The verses ("Думала-сами ищем...», «Исписанными блокнотами, слезами, шагами, сквотами...», «Не окрыляет. Не властвует. Не влечёт...») grammar structure has been analyzed. The study of the morphological picture of these and a number of other verses by Vera Polozkova makes it possible draw the conclusion that morphological potential of verbs and verb forms has been widely employed by the poetess. Actualization of participial and infinitive constructions, verbs finite forms is characteristic of the individual style. The expressive potential of the categories of voice, tense and aspect is used actively. Juxtaposition, selection and attraction are proved to help the poetess to emphasize the verb constructions grammatical semantics. Active juxtaposition and selection of participial forms are the poetess's individual style features.

Key words: poetic text, poetic morphology, dominant, compression, juxtaposition, attraction, individual style, Vera Polozkova.

Поэтический язык является сложной художественной системой, где множество разнородных элементов вступает во взаимодействие, создавая гармоническое единство. Достаточно подробно изучены такие поэтические ресурсы, как образность, ритмика, интонация, звуковая организация и синтаксический строй текста [1]. Высок поэтический потенциал морфологических форм и значений, актуализация которых служит важным средством поэтической выразительности.

Одним из основных способов выделения грамматических форм и значений является сгущение морфологически подобных единиц (см. подробно: [7, с. 7]). Результатом активного сгущения морфологических единиц в ряде случаев становится образование грамматической доминанты стихотворения или его фрагмента. Под доминантой морфологических форм понимаем сгущение грамматически подобных граммем, совокупность которых играет значительную роль в организации текста и служит средством создания определенных поэтических смыслов ([6, с. 373-394]; [5]).

Не менее активным способом грамматической актуализации служит соположение морфологических значений и форм [7, с. 5]. Морфологические категории, представленные в языке оппозициями, в обычной речи, как правило, не реализуются в противопоставлении значений, в то время как стихотворная речь широко использует не только антонимический потенциал лексики, но и грамматические возможности создания контраста и сравнения.

Способ сгущения морфологических форм связан с преобразованием обобщенных морфологических значений в частные. Результатом этого преобразования становится конкретизация семантики грамматической единицы и её усложнение. В монографии «Грамматические значения и поэтические смыслы: поэтический потенциал русской грамматики (морфологические категории и лексико-грамматические разряды имени)» [6] рассмотрены такие типы морфологических доминант, как числовые доминанты и доминанты числового противопоставления, доминанты одного рода и родового противопоставления, падежные доминанты, сгущение имен собственных и противопоставлений оним - апеллятив, притяжательных прилагательных, субстантиватов. В диссертации Е.В. Бувалец описана доминанта субстантивных биномов [2]. В работе Самсоненко кроме морфологических доминант имени исследованы глагольные доминанты наклонения и времени [5]. Однако актуализация форм и значений атрибутивных и личных форм глагола, противопоставление глагольных значений вида и времени, использование которых в современной лирике зависит от авторских предпочтений, до сих пор не было предметом специального исследования. Сгущение, как было доказано, является общепоэтическим приемом, типичным для русскоязычной поэзии XX-XXI веков, использование его также имеет идиостилевые отличия. Цель работы - проанализировать ряд стихотворений Веры Полозковой, в которых наблюдается сгущение различных глагольных форм (причастных, вида и времени, с отрицательными частицами) и противопоставление значений вида и времени.

Рассмотрим реализацию причастий и в стихотворении «Думала - сами ищем...». Здесь акцент делается на залоговой категории: 
Фатума план утрачен.

Люди богов сильней...

Только ты предназначен,

Небом завещан мне.

Огненною деснищей

(Чую ведь - на беду!)

Tbl на роду написан,

Высечен на роду,

Ласковоокой смертью,

Болью к родной стране -

Мильий, ты предначертан,

Ты предзагадан мне...

Количество причастий в этом фрагменте текста весьма велико. Отбор причастий исключительно страдательного залога подчёркивает предопределённость, нерушимость связи лирической героини и лирического адресата. Одновременно с этим акцентируется внимание на пассивности, не преднамеренности, а предначертанности выбора (завещан, высечен, написан, предзагадан), отсутствии у героев малейшей возможности сопротивляться воле судьбы. Тезис, высказанный в первых двух стихах (Фатума план утрачен. / Люди богов сильней), опровергается развертыванием стихотворения. Лексический окказионализм предзагадан с формальной точки зрения регулярен, он поддерживает причастную доминанту и образован путем аттракции причастных форм [9, с. 46-51]. Эта часть текста графически отделена от зачина и последующего фрагмента многоточиями. Возникает эффект смыслового противопоставления зачина и средней части, в которой утверждается, что фатум не утратил своего плана, а полностью его реализовал, о чём свидетельствует развитие повествования:

С новыми - не забыться,

Новых - не полюбить.

Мне без тебя не сбыться.

Мне без тебя не быть.

Сколько ни будь с другими

Да ни дразни судьбу-

Вот оно - твое иия,

Словно клеймо на лбу.

В этом фрагменте сгущение причастий сменяется сгущением инфинитивов (не забыться, не полюбить, не сбыться, не быть). Отсутствие значения лица у этих форм и у форм повелительного наклонения (не будь, не дразни), которые использованы в непрямом значении, поддерживает идею пассивности выбора героини, которая задана в первой части стихотворения. А отсутствие у этих глаголов значения времени способствует созданию эффекта бесконечного времени и пространства (инфинитив, совмещая свойства глагола и существительного, связан с обеими категориями континуума). Все, о чем повествует автор в данном фрагменте, предначертано героине навсегда и везде. В шести стихах этого фрагмента наблюдаем также сгущение частиц $\boldsymbol{\mu}$ и $\boldsymbol{\mu \boldsymbol { u }}$, семантика отрицания и отсутствия (о грамматической реализации понятия «отсутствие» см.: [4]) в которых усилена использованием предлога без-.

Стихотворение «Исписанными блокнотами, слезами, шагами, сквотами...» начинается полным страдательным причастием совершенного вида:

Исписанными блокнотами,

Слезами, шагами, сквотами,

Монетами - не банкнотами,

Да пряником и кнутом -

Отрыдано, оттанцовано,

Отпето, перелицовано,

Отписано - зарубцовано

Изаперто - на потом,

До лучших, чтоб - отбродившего

Откупорить - и хлебнуть. 
Как лиха. Как смыслла высшего -

Хмельную - шальную! - муть,

Когда уже будет сцежено,

Осозанано, прощено -

И боль отольется свежая

В рубиновое вино.

Мужчины, зачетьл, трудности,

Балконы в иветном белье -

Я буду судить о юности,

Как опытный сомелье.

Пока же еще - так солоно,

Так горько еще губам

Все то, что уже рассовано

По складам и погребам -

трепешущее, щемящее,

Упрятанное на дно...

- Игристое - настоящее,

Божественное вино!

Вторая строфа включает 7 кратких страдательных причастий, здесь сгущение формы очевидно и формирует доминанту строфы. Приставка от- повторяется в этой строфе в 4 страдательных причастиях отрыдано, оттанщовано, отпето, отписано, первое из которых авторское, а три других общеязыковые. Этот повтор префикса позволил бы читателю трактовать описанные действия как завершившиеся, лишённые потенциала к дальнейшему развитию, однако автор отмечает лишь отложенность предполагаемых возможностей - на потом, причем ряд причастий отделен от наречия тире, которое указывает на увеличение расстояния (паузу) между сущностью завершившегося момента и возможным будущим. Контекстуальный отпричастный субстантиват отбродивщего поддерживает видовременное значение предыдущих причастий, он соположен инфинитиву откупорить, который имеет значение вида, но лишен временных характеристик. Связь с предыдущим контекстом осуществляется в том числе за счет повтора приставки от- в глаголе и причастиях.

Причастия, употреблённые в следующей части стихотворения, сохраняют значения вида и также относятся к страдательному залогу, но за счет использования связки будет автор переводит повествование в план будущего времени: Когда уже будет сцежено, / Осознано, прощено... Значение предельности (завершенности) сохраняется неизменным, принципиально меняется значение времени - становится будущим (будет сцежено, отольется). Динамика следующей строфы сохраняет будущее время, меняя вид (буду судить), а затем постепенно переходит в настоящее лексически: Пока же еще - так солоно, / Так горько еще губам... Затем снова временная перебивка (Все то, что уже рассовано / По складам и погребам -), соположение оппозитов по виду и времени (Трепещущее, щемящее, / Упрятанное на дно -) и в коде - прилагательные, одно из которых отпричастный транспозит, передающий на лексическом и на грамматическом уровне значение настоящего времени: Игристое настоящее, / Божественное вино!

Последние строки стихотворения подтверждают активность, незавершённость процессов, которые формируют внутреннее состояние лирической героини. Чередование значений вида и времени создает впечатление причудливого орнамента, динамики временных планов, которые, перекликаясь друг с другом, образуют семантическое единство, которое подчёркивается прилагательным настоящее, имеющим два потенциальных смысла: настоящее - 'истинное' и настоящее - 'происходящее в данный момент'. Оба эти смысла актуализированы в стихотворении и влияют на восприятие его содержания.

Рассмотрим стихотворение «Не окрыляет. Не властвует. Не влечёт...».

Не окрыляет. Не властвует. Не влечёт.

Выброчено. Развеяно у обочин.

Взгляд отрешен или попросту обесточен.

Официант, принесите мне гамбургский счёт. 
Все эпилоги - ложь. Все дороги - прах.

Бог одинок и, похоже, серьезно болен.

Город отчаялся, и со своих колоколен

Он распевает гимн об иных мирах.

Воинам грехи отпущены наперёд.

Им не увидеть больме родимой Спартыл.

Я отдала долги. Я открыла картыл.

И потому меня больше никто не ждет.

Глаголы и причастия играют главенствующую роль структуре этого стихотворения. Особенность его поэтики заключается в том, что в отличие от большинства текстов, организованных морфологически вокруг глагольных форм, этот текст лишен динамики, он рисует статичную нарративную и эмоциональную картину. Смысловая «окончательность» событий и чувств, на наш взгляд, во многом связана с использованием семантики категорий времени и вида личных форм глагола и морфологических характеристик страдательных причастий.

Начинается стихотворение рядом форм настоящего времени с отрицательными частицами Не окрыляет. Не властвует. Не влечёт (...). Отрицательные глагольные ряды, как показано в работе $[8$, с. 65-70], в русскоязычной поэзии формируют мотивы, связанные с негативным или трагическим восприятием действительности (мотивы смерти, разлуки, невозможности жизни и счастья и под.). В данном фрагменте первый стих передает подавленное самоощущение лирической героини, оно развивается, переходит в мотив безысходности и находит окончательное разрешение в последней строке стихотворения $И$ потому меня больше никто не ждет, которая также заваршается отрицательной личной формой не ждет.

Зачин и концовка формируют кольцевую структуру текста и позволяют отнести данный текст к группе «НЕ-стихотворений», корпус которых в русскоязычной поэзии достаточно обширен (см.: [8, с. 81-89]). Специфика исследуемого текста состоит в том, что он имеет два повествовательных плана, первый из которых описывает внутренние ощущения лирической героини (именно он открывается первым, а заканчивается последним стихами текста), а второй рисует картину разрушенного города, которая и вызывает эти ощущения или вызвана ими. (Повышение в XX веке степени неопределенности поэтического текста отмечалось исследователями, см., например: [3]. Поэзия века XXI трансформирует неопределеннность в размывание поэтического нарратива, где происходит преобразование ее в многовекторность и поливариантность прочтения.)

Следующий фрагмент структурирован краткими страдательными причастиями прошедшего времени Выброшено. Развеяно у обочин. / Взгляд отрешен или попросту обесточен. Пассивность грамматической формы совмещена с отсутствием указания на действующий субъект (ответа на вопрос «Кем довершено действие?» нет, да он и не стоит), а словоформа отрешен вообще утратила семантику действия и лишь благодаря аттракции [9, с. 46-52] воспринимается как родственная причастной форме обесточен.

Второй стих Выброшено. Развеяно у обочин ассоциативно словом обочина связывает повествование с мотивом дороги, традиционным для русской поэзии. В третьем стихе Взгляд отрешен или попросту обесточен снова дается описание (как будто сделанное внешним наблюдателем) состояния лирической героини, которое обращено в четвертой строке Официант, принесите мне гамбургский счёт (...) к знаковому для русской литературной традиции понятию гамбургского счета (см.: [10]), а через него соотносится с идеей окончательного подведения жизненных и творческих итогов. Негативная семантика причастий (выброчено, развеяно, обесточен), поэтическая коннотация их и существительного обочина постепенно готовят читателя к трагическому тезису Все эпилоги - ложь. Все дороги - прах. / Бог одинок и, похоже, серьезно болен. Последний фрагмент лишен глаголов, настоящее время здесь становится бесконечным, пролонгированным, что графически и интонационно выражено тире, которое не соединяет и не разделяет слова, а растягивает время описываемого состояния. Эта же бесконечность, но уже предметная, связана с семантикой повторяющегося местоимения Bce.

Данный поэтический текст имеет двуплановую композицию, которую помогает дифференцировать использование в нём личных глаголов и причастий. Один план рисует разрушение города как завершённый процесс (Выброшено. Развеяно у обочин). Причастие 
развеяно символизирует конец существования отдельно взятого города, его последний день. Впечатление усиливается строками Воинам грехи отпущены наперёд. Им не увидеть больше poдимой Cnapmbl. Грехи отпущены наперёд, как тем, кто никогда не вернётся, город, который отчаялся и умирает (он распевает гимн об иных мирах), этих воинов больше в себя не примет. Это единственный фрагмент стихотворения, где противопоставлены перфектная форма прошедшего времени (отпущены) и инфинитива (не увидеть), причем инфинитив использован с отрицанием. Отсутствие у инфинитива времени значимо, как и использование частицы не. Соположение этого причастия и ифинитива, как и причастие обесточен, которое сопровождается прилагательным отрешён, формируют мостик между именем и глаголом, между временем и пространством этого текста. При этом все формы передают значение вида (оно во внутренней форме сохранилось даже у прилагательного). Адъективная словоформа, не полностью лишаясь категориальных признаков глагола и его форм, становится дополнительным маркером перфективации. Таким образом, выраженная краткими страдательными причастиями совершенного вида функция завершённости, которую мы можем наблюдать на обоих повествовательных планах, позволяет читателю воспринимать текст как единое целое, охватить и синтезировать как физический план разрушения города, так и душевное состояние лирической героини.

Исследование морфологического рисунка этих и ряда других стихотворений Веры Полозковой позволяет сделать вывод о том, что поэт активно использует морфологический потенциал глаголов и глагольных форм как средство поэтической изобразительности и выразительности. Для ее идиостиля характерна актуализация причастных форм, инфинитива и личных форм глагола. Особенно активно реализуются возможности категорий залога, времени и вида. Соположение, отбор и аттракция помогают выделить грамматические значения и формы. Активное соположение и отбор причастных форм, по нашим наблюдениям, являются идиостилевой характеристикой лирики поэта.

\section{ЛИТЕРАТУРА}

1. Бабенко Л.Г. Филологический анализ текста. Основы теории, принципы и аспекты анализа: Учебник для вузов. М.: Академический проект; Екатеринбург: Деловая книга, 2004. $464 \mathrm{c}$.

2. Бувалець О.В. Подвійні субстантивні конструкції в російській поезії XX - XXI століть: автореф. дис. ... канд. філол. н. Спеціальність 10.02.02 - російська мова. Харків, 2018. 20 с.

3. Ковтунова И.И. Поэтический синтаксис. М.: Наука, 1986. 206 с.

4. Радчук О.В. Лексико-грамматическая корреляция абстрактных понятий (отсутствие - отрииание - пустота) // Studia methodological, Ternopil Volodymyr Hnatiuk National Pedagogical University, JanKochanowski University in Kielce, Issue 41, 2015, P. 17-23.

5. Самсоненко H.I. Морфологічна домінанта поетичного тексту (на матеріалі російськомовної поезії XIX - XXI століть): автореф. дис. ... канд. філол. н. Спеціальність 10.02 .02 - російська мова. Харків, 2018. 20 с.

6. Скоробогатова Е.А. Грамматические значения и поэтические смыслы: поэтический потенциал русской грамматики (морфологические категории и лексико-грамматические разряды имени): Монография. Харьков: НТМТ, 2012. 480 с.

7. Скоробогатова Е.А. Поэтическая морфология как направление лингвопоэтики и лингвокреативная практика филологического эксперимента // Русская Филология. Вестник Харьковского национального педагогического университета имени Г.С. Сковороды. Харьков, 2018. № 4 (66). С. 3-10.

8. Скоробогатова Е.А., Минина Н.С. Грамматические значения и поэтические смыслы: стиховая актуализация служебных частей речи: монография. Харьков: ФЛП Бровин А.В., 2017. $160 \mathrm{c}$.

9. Скоробогатова О.О. Теорія граматичної атракції О.О. Потебні в дослідженні граматики віршового тексту // Мовознавство. 2015. № 6. К.: Інт. мовознавства ім. О.О. Потебні, 2015. C. $46-51$.

10. Шкловский В.Б. Гамбургский счет: Статьи - воспоминания - эссе (1914-1933). М.: Советский писатель, 1990. 544 с. 